\title{
Beatriz Preciado. Manifiesto contrasexual. Barcelona, España: Anagrama, 2011 [2000]
}

\author{
Beatriz Preciado. "The contra-sexual manifesto"
}

Nicolás Ried ${ }^{1}$

Manifiesto contrasexual fue escrito en francés por Beatriz Preciado (Burgos, 1970), publicado en Francia en 2000. Solo hacia 2002 fue publicado en castellano, impreso en España. A Chile llegaba de contrabando desde Europa; la explosión del preciadismo se dio en 2004, cuando la pensadora visitara el país (aún no existían como libros ni Testo yonqui de 2008, ni Pornotopía de 2010). Para recibirla, como sucede cuando visita un intelectual famoso, los escaparates de las librerías se llenaron de manifiestos, y prontamente se agotaron: desde 2004 hasta 2011, la sequía fue manifiesta. Sin embargo, la sequía es un símbolo interesante como objeto de análisis: la ausencia del libro fue solamente fetichista, pues si bien como libro-objeto no podía encontrarse ni apropiarse, el texto circulaba sin problemas por todo el mundo, ya sea en formato fotocopia o digital. Las ideas de Preciado eran, sin duda, conocidas.

La editorial Anagrama, en 2011, reimprimió el mítico Manifiesto contrasexual, terminando con la sequía para quienes padecen del fetichismo libresco. Así, cobra corporalidad un texto mítico para comprender el desarrollo actual de feminismo, del posfeminismo, y de las políticas de la resistencia, provenientes de los esquemas de análisis postestructuralistas.

En el libro, tras presentar los principios de la sociedad contrasexual, Beatriz Preciado inserta un "contrato contrasexual", una forma jurídica que presenta a lo sexual como una manifestación pública, entendiendo desde ya lo sexual como público, cuya fuente no es el Estado sino el individuo. Pero ¿cómo entender este contrato? ¿Es la única manera de formar parte de la sociedad contrasexual? ¿A qué responde este acto literario? ¿Cuál es la fuerza política de este acto? Ese contrato debe comprenderse como un ejemplo de acto político, nunca como una regla.

$1 \quad$ Estudiante de Licenciatura en Ciencias Jurídicas y Sociales de la Universidad de Chile. Ayudante ad honorem de las cátedras de Filosofía moral y de Teoría social. Organizador de las Primeras Jornadas Estudiantiles de Teoría de Género, de la Universidad de Chile. Diplomado en Conceptos de lo Político (CAIP). nicolasried@gmail.com 
"Lo sexual es político" fue un lema, un símbolo de la lucha feminista del siglo XX. La carga que esta idea contiene es particularmente intensa cuando la analizamos desde la forma en que las luchas feministas han trascendido hacia otras luchas sociales; el feminismo como paradigma de la reflexión sobre la libertad: lo sexual es político, y siempre lo fue.

Michel Foucault, ante la pregunta insistente sobre cuáles son los mecanismos políticos de resistencia que se pueden manifestar desde el análisis posestructuralista, en relación con el ejemplo que presentan las luchas feministas, dijo: "Debemos crear una cultura. Debemos realizar creaciones culturales. Pero ahí topamos con el problema de la identidad" (Foucault, 2010a: 1048). La lucha por lo sexual es política, es pública; queda claro que la sexualidad es parte de la política y del derecho cuando vemos la antigua legislación sobre sodomía, la presente normativa sobre matrimonio heterocentrado, y la futura discusión sobre aborto. La creación de esa cultura es comunitaria, es pública; tal como crear un lenguaje privado no es posible, crear una sexualidad privada tampoco lo es. Así, la propuesta foucaultiana se presenta como un lazo entre el feminismo, la ética y la política: la construcción de sí, a base de una ética del cuidado de sí, atendiendo a una práctica relacional.

Ante una nueva insistencia, Foucault (2010b) responde al cómo crear esa cultura: mediante prácticas de la libertad, entendiendo la libertad como la condición ontológica de la ética, y a la ética como la forma reflexiva que adopta la libertad. El sadomasoquismo y el fist-fucking, dirá el filósofo. Burdo sería pensar que Foucault refiere actos de libertad determinados: ciertamente, un puño en el ano no hace libre a alguien. Lo relevante de llamar práctica a aquella propuesta, es que entiende la política como una forma de vida, no como una contingencia; las prácticas del sadomasoquismo y del fist-fucking se manifestaban en las comunidades leather, las subculturas de los años 70 y 80 que se presentaban como formas alternativas de vida ante el capitalismo tardío que revisó el pensador francés. Sadomasoquismo y fist-fucking, como casos básicos de la desexualización del placer, de la desgenitalización de las prácticas sexuales, pero antes que eso, la subversión de la identidad sexual a base de la imaginación, a la creación de vidas paralelas a las normalizadas, a las establecidas.

El problema que presenta la propuesta de Michel Foucault es que cristaliza las formas en las cuales se puede pensar la subversión, la emancipación: si todos somos sadomasoquistas, se establece una norma, y por tanto esa práctica no es ya subversiva de la identidad. Lo que muestra, por tanto, la propuesta mencionada consiste en pensar a la ética como la forma reflexiva que adopta la libertad, esto es leer la propuesta foucaultiana como un hacer antes que como un ser del sujeto: la libertad se practica.

Judith Butler, conocida como una de las fundadoras de la queer theory, comprende la estructura foucaultiana y se convierte en su heredera: tener prácticas es fundamental, mas estas no pueden ser únicas y estáticas. Dice la filósofa:

"Si soy alguien que no puede ser sin hacer, entonces las condiciones de mi hacer son, en parte, las condiciones de mi existencia. Si mi hacer depende de qué se me hace o, 
más bien, de los modos en queyo soy hecho por esas normas, entonces la posibilidad de mi persistencia como 'yo' depende de la capacidad de mi ser de hacer algo con lo que se hace conmigo" (Butler, 2006: 16).

Butler entiende el género como performance, lo que implica que el sexo y el género son construcciones culturales, ninguna de ellas natural y prediscursiva: tanto la ciencia como la cultura son creaciones humanas, son decisiones políticas. Así, una práctica crítica que investiga Butler es la del drag: si "hombre" y "mujer" son formas "correctas" de seguir una regla, el drag muestra lo paródico de las reglas del género, ya que si el género no fuera performado, al ver a un o una drag no veríamos una parodia, sino a un hombre o a una mujer; el dato, dirá Butler, por el que reconocemos la parodia consiste en que el género no es natural. La performance de género, en este sentido, es la conducta que un sujeto realiza en el marco de una identidad de género, en oposición a la noción de performatividad del género, que se refiere a la manera en que modifica el mundo el género asignado a un determinado sujeto: la performance es la interpretación de un rol (role playing) impuesto, mientras que la performatividad son las consecuencias políticas y sociales de dicha interpretación: de usar falda se puede seguir, en determinado contexto, la performance femenina, pero de esa performance no debería seguirse un sueldo menor al de un sujeto que performe el género masculino, por ejemplo.

En esta discusión se inserta la autora española. Beatriz Preciado aparece en la línea hereditaria de Foucault y Butler, extendiendo y superando las lecturas de sus antecesores: al insertar el contrato contrasexual, después de los principios de la contrasexualidad, y antes de las prácticas de inversión sexual, Preciado realiza parodia y política. Parodia, al reapropiarse de los usos lingüísticos jurídicos, manifestación paradigmática del lenguaje del poder estatal; política, al releer la ética como la forma reflexiva de la libertad en el sentido foucaultiano: fue el sadomasoquismo, fue el drag, ahora una nueva forma de pensar la subversión de la normatividad está dada por las prácticas de inversión sexual.

El problema del género para Judith Butler consistía en que:

"Si se refuta el carácter invariable del sexo, quizás esta construcción denominada "sexo" esté tan culturalmente construida como el género; de hecho, quizá siempre fue género, con el resultado de que la distinción entre sexo y género no existe como tal [...] El género es la estilización repetida del cuerpo, una sucesión de acciones repetidas - dentro de un marco regulador muy estricto- que se inmoviliza con el tiempo para crear la apariencia de sustancia, de una especie natural de ser" (Butler, 2007: 55 y 98).

Para Beatriz Preciado se presenta como una relación en que:

"Los hombres y las mujeres son construcciones metonímicas del sistema heterosexual de producción y de reproducción que autoriza el sometimiento de las mujeres como fuerza de trabajo sexual y como medio de reproducción [... L La identidad sexual no es la expresión instintiva de la verdad prediscursiva de la carne, sino un efecto de reinscripción de las prácticas de género en el cuerpo" (Preciado, 2011: 18). 
No quedándose en el drag butleriano, Preciado considera la reasignación de identidades subversivas desde la crítica biopolítica, en cuanto asignación policial de identidades de género. Así, ya no solo no hay vidas que sean masculinas o femeninas, sino que tampoco hay prácticas que sean masculinas o femeninas, no hay hormonas que sean masculinas o femeninas. Las prácticas de inversión sexual, propuestas por Preciado, detonan un sistema de asignación biopolítica del género en función de determinadas forma de hacer de lo sexual y de lo político: tal como podemos deconstruir ciertas imposiciones sobre el know-how de la sexualidad, podemos hacerlo con el conocimiento práctico sobre lo político: no hay solo un sistema fascista, también hay prácticas que lo son, y que deben ser erradicadas de un sistema que se pretende político.

Diferencias y repeticiones, es lo que hay en el texto de Preciado, en diversos planos: el texto, como tejido conceptual, presenta una continuidad con los elementos teóricos que sirven de fundamento para las tesis, estructurando relecturas de Foucault, Derrida y Butler; por cierto, el texto, entendido esta vez como metatexto, se vuelve particularmente interesante: el orden del discurso que propone Preciado no solo nos dice una propuesta contrasexual, sino que también la muestra: no solo habla de la parodia del género, sino que al contener un articulado de principios y un contrato contrasexual se apropia y parodiza el lenguaje del poder, el lenguaje del derecho, el lenguaje de la ley. Hacia el final, en el "ejercicio de lectura contrasexual", la práctica intelectual se confunde con la práctica política, cobrando particular importancia la historia de la publicación misma de este manifiesto: un texto que difícilmente se encontraba en librerías, que era de culto, que era necesario para iniciar cualquier investigación sobre posfeminismo y teoría queer; un libro conocido y desconocido, ubicado e inubicable.

Las secciones del libro se presentan a sí mismas como un elemento crítico, como una especie de fractal de la misma teoría que expone: lo primero es exponer la pregunta por la contrasexualidad, que Preciado sitúa y origina en la obra de Michel Foucault; sin embargo, la presentación de este aparato teórico-conceptual como una versión crítica de lo que conforma la sexualidad y la política, no puede quedarse en el mero aparato conceptual. Así, la segunda sección consiste en los principios de la sociedad contrasexual, en que se enumeran en forma de artículos los preceptos que servirán como criterio para evidenciar lo contrasexual. Seguido de la normativa contrasexual, se presenta un ejemplo de contrato contrasexual, que señala las formas de manifestación del consentimiento entre quienes participen de esta práctica. Terminada esta sección prologar, lo que sigue es un artefacto en sí mismo: un conjunto de prácticas de inversión contrasexual y teorías, es decir: praxis de la contrasexualidad. Lo interesante en este sentido, consiste en que las teorías que presenta Preciado son relecturas de Foucault, Butler y Derrida, que por sí mismas constituyen praxis de la contrasexualidad, en el sentido que no es estrictamente "teoría", pues esas relecturas son precisamente las que permiten la comprensión crítica de todo el aparato contrasexual: las lecturas tradicionales no permiten dar cuenta de lo contrasexual, por lo que el releer a los y las pensadoras es un acto político. Finalmente, un ejercicio de lectura contrasexual, permite dar cuenta del estatus mismo del libro: ¿cuál es la posición estructural del 
mismo Manifiesto contrasexual? ¿Es coherente que el manifiesto sea un libro y no un video, por ejemplo?

La posición de Preciado, en definitiva, es antimetafísica. El proyecto de Preciado consiste en tomarse en serio la argumentación de Butler (tal como ella se toma en serio la argumentación de Foucault), basado en que "biología no es destino", cuya traducción aquí sería "biopolítica no es destino" : las identidades subversivas no responden a determinadas nociones científicas que las determinen, tal como tampoco deben responder a adscripciones políticas que las sacralicen. Preciado consigue establecer una filiación intelectual con los autores de la filosofía política crítica, en cuya lectura consigue presentar la sexualidad como un modo de producción más grande que la producción de placer genital: si el principio de desexualización, presentado por Foucault, significa algo, esto es que las formas del placer sexual son desconocidas y su finalidad es el erotismo (ars erotica), no la determinación y clasificación de los sujetos (scientia sexualis). Así, la lectura de Preciado de los dildos, como caso básico de la desexualización del placer es fundamental: la comprensión de que las manos y el pene son dildos de carne, y no que el dildo es un pene de plástico, permite comprender incluso al texto como un dildo del intelecto. La masturbación mental también tiene sus dildos, y eso es político: la tesis que allí subyace dice que la teoría es praxis, que los lugares académicos son tan políticos como cualquier otro, que la producción cultural es también un espacio de la sensibilidad, de la visibilidad.

\section{BIBLIOGRAFÍA}

Butler, Judith (2007): El género en disputa. El feminismo y la subversión de la identidad. Barcelona, España: Paidós.

Butler, Judith (2006): Deshacer el género. Barcelona, España: Paidós.

Foucault, Michel (2010a): "La ética del cuidado de sí como práctica de la libertad". En sus: Obras esenciales. Barcelona, España: Paidós.

Foucault, Michel (2010b): "Michel Foucault, una entrevista: sexo, poder y política de la identidad". En sus: Obras esenciales. Barcelona, España: Paidós.

Preciado, Beatriz (2011): Manifiesto contrasexual. Barcelona, España: Anagrama. 